\title{
"Doing" social inclusion with ELSiTO: Empowering learning for social inclusion through occupation
}

\author{
Sarah Kantartzis ${ }^{\mathrm{a}, \mathrm{b}, *}$, Marion Ammeraal ${ }^{\mathrm{b}, \mathrm{c}}$, Saskia Breedveld ${ }^{\mathrm{b}}$, Lieve Mattijs $^{\mathrm{b}}$, Geert $^{\mathrm{b}}$, Leonardos $^{\mathrm{b}}$, \\ Yiannis $^{\mathrm{b}}$, Stefanos ${ }^{\mathrm{b}}$ and Georgia ${ }^{\mathrm{b}}$ \\ ${ }^{\mathrm{a}}$ Hellenic Association of Occupational Therapists, Athens, Greece \\ ${ }^{\mathrm{b}}$ ELSiTO learning partnership

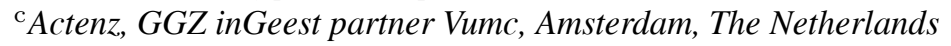

Received 15 January 2011

Accepted 18 October 2011

\begin{abstract}
Objectives: The European partnership ELSiTO aimed to develop understanding of the nature and processes of social inclusion for persons experiencing mental illness. Participants: Partners were from Belgium, Greece and the Netherlands with over 30 members including mental health service users, occupational therapists and other staff.

Approach: A knowledge-creation learning process was used during four international, experiential, visits and local meetings, which included visiting and describing good practice, telling stories of experiences, reflection and discussion.

Results: The partnership developed understandings of the nature and process of social inclusion, including both subjective and objective aspects interrelated with the doing of daily activities in the community. Members' work-related experiences, illustrated through their stories, depict the subjective aspects of social inclusion as they are shaped and framed by the objective conditions within a variety of work opportunities. Experiences in paid work, supported employment and voluntary work may both threaten and enhance mental health. Features of successful (voluntary) work experiences are identified.

Conclusions: The importance is revealed of looking critically at current understandings of work and to move beyond a narrow focus on paid work in order to provide a range of work opportunities that will empower the individual's potential and promote inclusive communities.
\end{abstract}

Keywords: Work, volunteering, social inclusion, mental illness, stories

\section{Introduction}

Promoting social inclusion is a key target of the European Union to alleviate poverty and exclusion, with almost $20 \%$ of the population at risk of poverty [14], while persons with mental illness are at considerable risk of exclusion due to stigma, unemployment and poverty [20]. Access to quality employment is seen to

*Address for correspondence: Sarah Kantartzis, Papanastasiou 4, Melissia 15127, Athens, Greece. Tel.: +30 6944410 963; E-mail: skanta@ath.forthnet.gr. be a sustainable way out of social exclusion [13], and a key component of the European disability strategy 2010-2020 [11]. Work is important, not only as the primary means by which people can support themselves and their families, but also due to socio-historical processes that emphasize the moral superiority of work and the stigma of not working.

However, enabling participation and inclusion through work or other activities, despite symptoms due to mental illness, is a complex process and requires attention to be paid to both structural and individual factors. A need to explore new ways of working towards social inclusion led a group of mental health service 
users and professionals from three European countries to work together in the ELSiTO (Empowering Learning for Social Inclusion Through Occupation) learning partnership. This unique opportunity for shared learning through the lived experience of inclusion, enabled these ELSiTO members to develop an understanding of the nature of social inclusion and the processes of change that are undertaken by all involved.

This article will provide a brief description of this project and its results, and will explore these results in relation to opportunities for and engagement in work (of all kinds), through excerpts from the members' stories of their experiences of work ${ }^{1}$ and a discussion of the structural conditions promoting these opportunities. The importance of work is illustrated but also the experienced difficulties with maintaining a paid job, staying healthy and feeling included. The alternative of voluntary work is illustrated as providing many of the essential conditions for social inclusion.

The paper concludes with the importance of looking critically at the current discourse around work (neoliberal politics and individual responsibility, the current focus on voluntary work in this dedicated EU year), and its potential impact on the subjective experiences of work. This invites consideration of the possibilities and implications of moving beyond a narrow focus on paid work in order to provide a range of work opportunities which will empower the potential and recovery of all, promoting inclusive communities.

\section{Background and context of the ELSiTO partnership}

Within the European Union importance is given to the social inclusion of all citizens, with an awareness of the particular needs of vulnerable groups, whether this is due to age, nationality or health status. The new millennium has also seen in occupational therapy recognition of the impact of structural conditions affecting occupational opportunities (occupation being defined as "all the things that people need, want, or have to do" [5], and not just associated with work). This has resulted in a corresponding awareness of the limitations of individual, disease-based interventions and need to explore more effective approaches, crossing traditional boundaries of responsibility and control, in order to

\footnotetext{
${ }^{1}$ The complete stories may be found on the ELSiTO website: www.elsito.net.
}

empower health and well-being for the individual and the community.

From this background, in 2009 a group of mental health service users and mental health professionals from Belgium, Greece and the Netherlands came together to explore social inclusion. ${ }^{2}$ This learning partnership, known as ELSiTO, was funded for two years (2009-2011) as a Grundtvig Learning Partnership under the Life Long Learning programme of the European Union. This funding enabled the partners to undertake four learning visits over the two year period. A total of 38 people were actively involved in ELSiTO, while local partnerships involved many more.

\section{The ELSiTO partnership and the learning process}

The main aims of the partnership were to empower mental health service users to develop the competences to participate in community based activities (occupations), especially work and leisure activities; to identify the pedagogical approaches that constitute the collaborative learning between service users and staff that leads to the empowerment of service users for participation in such activities; and to develop a network of stakeholders involved in community projects throughout Europe for the exchange of good practice, communication and to facilitate emerging projects.

\subsection{Theoretical framework and methodology}

The group followed a process similar to the knowledge-creation metaphor of learning [19]. A trialogical learning process, consisting of the interaction between members within the shared activities (locally and internationally) of everyday living, workshops and visits to projects, enabled ELSiTO members to explore existing knowledge and to uncover and develop new knowledge regarding the nature and the processes of social inclusion.

Knowledge was developed in a disciplined way: questions were asked and explored, discussions and reflections were recorded in notes, written evaluations completed. Good practices were described following a template and narratives of members' experiences were gathered. Learning social inclusion took place both

\footnotetext{
${ }^{2}$ The three partners are: the Hellenic Association of Occupational Therapists, Greece; Actenz GGZ inGeest partner VUmc, The Netherlands; Hogeschool - Universiteit Brussel, Belgium.
} 
at an individual, experiential level leading to personal change and development, but also at a shared, theoretical level, presented in the results and conclusions of the group.

All participants came to be known equitably as "ELSiTO members", recognising our common learning process and challenging the hierarchical nature of existing roles of "therapists and clients" and the narrow definition of social exclusion as something only experienced by marginal groups. At the same time we acknowledged the expertise of service users on matters of mental illness and it was understood that all members brought into the learning partnership their own unique skills, knowledge and experiences.

\section{Understanding social inclusion}

The group developed an understanding of social inclusion that includes two essential and inter-related aspects - the objective and the subjective - through the actual "doing" of inclusion in everyday activities in the community.

The objective aspect has to do with the conditions that are necessary (laws, places, financial resources, logistic opportunities, accessibility etc.), while the subjective aspect has to do with the personal experience of inclusion and is connected to elements such as safety, trust in others, having the opportunity to grow or to be yourself. Therefore, one can be objectively "counted" as being included, while still subjectively experiencing exclusion.

The objective and subjective elements come together through "doing" in community based activities. Ongoing development and change through facing challenges and learning during daily, small and ongoing occupations and activities, together with feeling connected to others by doing things together, with and for each other, are common to all aspects of social inclusion as we experienced it in ELSiTO.

However, these elements come together and grow over time. The group described it in this way: "In the beginning, one can talk about readiness, being able, to begin the process, when we still feel very uncertain and maybe disorganised, and feel the need for support. There will always come a time that we feel strong enough, with the force and energy, to start working towards our social inclusion into our local community. As the process continues it will be important to move away from a position of dependency to be more autonomous. This is not a smooth path and may include friction with others around us (e.g. staff and carers) as we move back and forth across the borders between dependency and autonomy. It is important that we follow the tempo of the process even if it is very slow. It has no sense to force it. We need to take small steps".

\section{Understanding social inclusion and work - the stories}

Our understandings of the nature and process of social inclusion are evident in the stories of the members of ELSiTO regarding their experiences of gaining and maintaining (paid) work. Their narratives reveal the complex interrelation of subjective and objective factors as they engage in an ongoing process of finding work opportunities that provide them with a sense of using their skills and ongoing self-development, and the satisfaction of feeling a valuable member of society. However these narratives also reveal the urgency to look again at the place of work in relation to social inclusion. A number of questions emerge: to what degree can paid work support social inclusion? Can voluntary work provide a valuable alternative? If it can, how can voluntary work be supported and also organised in such a way as to offer the means to financially maintain oneself?

The stories are of seven members from the three countries, four men and three women. Three of these members took part in the learning visits abroad. They have a range of work experiences including full time paid employment, sheltered and supported work and voluntary work.

\subsection{The importance of work}

The stories illustrate a number of key factors regarding the individual and their relationship with work, of all types. Perhaps most striking is the often unspoken assumption that one should work, that it is an important part of the everyday, concurring with studies in this area $[6,9,21]$.

"Adaptation to work plays an important role in the life of a person" (Stefanos).

The inability to work may be linked to acknowledgment of the mental illness:

"Soon though, the psychiatric problem presented. What I remember characteristically is that I did not want to accept it. I tried to work, but the three attempts I made were unsuccessful" (Yiannis). 
While, with recovery, a paid job that suits oneself becomes a primary goal:

"Finally, I stopped working for my uncle because, although he paid me well, it was not a real paid job and I wanted to focus on working towards my first paid job. I worked together with a jobcoach. We organised practical experience times, sort of try-outs, with only one aim: having a paid job that matches me!" (Geert).

"When I was employed, I believed that finally I too would be a useful person in the society, that I would offer many things in my work, I would explore more of my potentials that I had but were hidden, and that I would evolve as a person, spiritually and emotionally" (Leonardos).

Apart from this overall sense that work is essential, specific beneficial characteristics of work were mentioned: to structure time, to give opportunities for social contacts, to be useful to society, and to use one's talents.

\subsection{Structural supports for work}

In all three countries persons with mental illness who are unemployed, receive some benefits from social security schemes. At the same time a return to paid employment is encouraged through a combination of financial incentives to employers (for example in Belgium through the Activa card given to all long-term unemployed looking for work), and a variety of schemes and programmes to support the individual. Individual placement and support (IPS) is promoted as a method in mental health organizations in all three countries, its effectiveness over traditional training schemes demonstrated through two major RCT studies [2,3]. Additionally, in Belgium and the Netherlands persons with difficulties with work can receive support through coaching on the job. In Belgium: GTB (Gespecialiseerde trajectbegeleiding) - jobcoaching, is connected to the national employment service (VDAB) and involves a period of practice in actual jobs. In the Netherlands jobcoach personal support is connected to the national endowment fund (UWV), providing benefit and reintegration services [23]. In Greece people with disabilities are eligible for training schemes through the Manpower Employment Organization (OAED).

However, there continue to be problems in the integration of out-of-work benefits with in-work supports [13], leading to confusion regarding eligibility, and potentially acting as a deterrent to paid work. For example Saskia mentions how it was not worth working as a temporary physiotherapist as then she had to pay back her earnings to the social services when she got her unemployment benefit. The development of Social Enterprises goes some way towards resolving these problems. For example the Koi.S.P.E in Greece have a unique administrative and legal structure as a working cooperative and members/workers are permitted to keep their benefits [17].

Additionally, it is important not to ignore the large percentage of persons who do not manage to achieve participation in work despite the various schemes. Even in IPS programmes, non success rates are still high $45 \%$ in the Burns et al. [2] study of six European countries, and $61 \%$ in the Netherlands study [3].

\subsection{Structural supports influencing subjective experiences}

Structural supports do more than provide the objective conditions of employment. They also influence the subjective experience, in individual ways for each person. Supported employment and job try-outs may provide valuable understanding of the type of work that will suit the person, but at the same time may "mark" the person in some way. Geert has experienced both of these aspects:

"And now I know more what I want: part time, free weekend, structured hours, a little shop, a small number of colleagues. Also I will tell every boss about all my voluntary work with pride, about my experiences and what I have learnt. And I will give them the Activa-card with its many advantages for them".

"I stopped job coaching and now do everything myself. I had only wanted my coach for making contracts and that's all, and what disturbed me was that on the contract, next to her signature, stood the name of the sheltered housing. I don't want any connection with that organisation because then I will lose my pride" (Geert).

Training courses and job coaching may give valuable experience (and raise hopes), but do not always lead to job opportunities:

"I also did a short course, learning to be a substitute employee at a crèche via a job agency. I wasn't invited for any job afterwards" (Saskia).

"There was a sports shop that gave me a chance to apply for their free job but when I went for the interview the boss said 'I am honestly searching for a woman". I started at a shop to sell sport 
shoes for a trial period for 3 hours, but their shop is known as 'slavery period' - they have no job but they let you work 3 hours for free” (Geert).

For some, finding a subsidized job is only the first step, they then may feel they do not have the necessary skills:

"Then I got a job as an administrative employee in an architect's center. It was a subsidized job for long-term unemployed. I did it for just half a year. It was hard because I had no experience in that kind of work. I didn't really feel at home" (Saskia).

"I had not received adequate training in computers ... there was no ongoing educational programmes for working service users" (Leonardo).

\subsection{The subjective experience of work}

Members' stories demonstrated that it was on the whole the nature of the subjective experience that determined long term success. For all, paid work seemed to cause considerable stress and pressure, confirming European reports [15].

Anxiety may be caused by working full time with fixed hours: "it felt like a pressure from which I couldn't escape" (Saskia), but also by flexible shifts: "I don't want flexible hours, with different hours each week and only Sunday free" (Geert).

The environment did not always feel safe and problems with colleagues were often the catalyst leading to either quitting or illness (see [4] for further discussion).

"I had conflicts with my bosses... and it was difficult for me to work in a team" (Georgia)

"When I got back from a holiday my nearest colleague treated me in a nasty way which upset me. I never went back afterwards" (Saskia).

"For me, the content of the work isn't the real problem. Most of the time, the things I have to do, I can do okay. But the social context and the responsibility are triggers and give me a lot of stress, with relapses as a result. So I've chosen in favour of my well- being and mental stability” (Lieve).

Finally, as Lieve experienced, failing from her paid job when she became ill again, made it twice as painful: "Depression and the feeling of having failed were the result: I didn't only get sick again, I lost my job too. And that was twice as painful" (Lieve).

The stories demonstrate the ongoing learning and development that the members have undertaken in order to find work that best fits their abilities, skills, and interests. The process is individual, making considered choices about work that will support their mental health and well-being, balancing vulnerabilities with talents. Both Saskia and Lieve ultimately decide that voluntary work best supports they needs and their health, Yiannis and Leonardos are in supported employment but active in voluntary work, while Geert is aiming for paid employment.

\subsection{Voluntary work}

In Belgium and the Netherlands voluntary work is supported by various government schemes aiming at inclusion and participation for all. Voluntary work may have the disadvantage of not fitting the person or being rather boring: "For a while I did some volunteer work, but then I got fed up with all that kind of work because it didn't fit me and wasn't challenging enough" (Saskia), but on the whole offered members stimulating opportunities to use and develop their unique knowledge, skills and experiences, which may facilitate the development of self-identity and sense of competence [18]. In comparison to paid work, voluntary work was more flexible, one could "escape" if one needed to and people were seen to be more understanding.

"In 1998, I suffered from psychosis. During the recovery, I worked as a volunteer for Oxfam Fairtrade, as a sales person in the shop and at the market-place. Working there was a very good way to structure my day and to have some social contacts outdoors. . Ifelt accepted in the group and if things didn't go well for me, it was always possible to talk about it with the shop-manager. He didn't always understand, but most of the time we found a way to deal with it" (Lieve).

Also one could feel that one is doing something challenging, useful, or using one's experiences to help others empower themselves.

"I applied to be a volunteer. Finally I found a challenging project were I could do something with my talents... I enjoyed being in a place where there was so much creativity, a positive and friendly atmosphere and where we could work together" (Saskia).

Also, it is of considerable importance that voluntary work was able to support the recovery of mental health, by offering safety, space and stability during times of crisis. 
"For me it was also a very difficult period of my life because my panic disorder came into existence. At that time, more than ever, I needed a safe place to be that could distract me from my extreme daily tension and stress. At the same time I could take part in all kind of activities and experiences that I liked and were suitable for me. There was always space to find possibilities to make it work for me, taking my boundaries into consideration" (Saskia).

Members have slowly discovered for themselves opportunities for voluntary work that best suit their own needs and skills. Four of the members are working in forms of voluntary work that utilizes their experience of mental illness - Yiannis and Leonardos are both presidents of associations of mental health service users, Lieve and Saskia work with client-groups who advise professionals, while Lieve also talks to school children about mental health.

Lieve eloquently expresses her decisions around her work:

"Maybe my responsibility in society isn't that big, I think it's for everyone's best (even society) to stay healthy and keep myself away from the hospital. It can be frustrating sometimes, but I've learned that I can't always get what I want. . Since I quit working in a paid job in 2005, I've been able to stay at home and be stable. In my voluntary work my vulnerability is understood and I feel like I'm doing something useful. That is very satisfying.

I believe it's important to do something that gives you a feeling of having sense. And bearing my vulnerability in mind is not a sign of weakness, but rather it's best to follow my intuition and do the things that feel okay..." (Lieve).

\subsection{Paid work or voluntary work?}

The very different characteristics of paid and voluntary work are evident, supporting discussions that many types of contemporary paid work do not provide the opportunities for the development of personal competence and self-identity which it has been traditionally thought to do [25]. This is obviously of concern for all workers, but particularly for those in the recovery process from mental illness. Much supported work is low-skilled, low-income, with no opportunities for career development [16]. Work environments may also cause high levels of stress, or over-occupation, "with too much stimulation from an intrusive environment" [9, p. 189]. It would seem that voluntary work, having less pressure from financial targets, often offering more intel- lectually stimulating and interesting opportunities, enables more personalised and flexible working environments, permitting better occupational balance for each individual.

In both the Netherlands and Belgium this would appear to be recognised with a pro-active policy for promoting voluntary work. Additionally, in the Netherlands, working as a volunteer enables one to be exempt from paid work for six month periods. The European Year of Volunteering 2011 has the expressed aim to raise awareness of the value and importance of volunteering. Increased skills and confidence for the individual together with increased community cohesion and services are seen to be the benefits of volunteering [ 5 , 12].

However, further exploration is required regarding the degree to which the EU (and the general public) sees volunteering to be of equal value to paid work, or more as something to do alongside or after retirement from a paid job. While volunteering opportunities are very important for persons recovering from mental illness who struggle to find and maintain a paid job, it is important that this does not increase stigmatization and a sense of exclusion.

\section{Supporting voluntary work experiences}

The ELSiTO members have identified factors supporting voluntary work, which are also valuable to consider in relation to the development of conditions for successful paid work. These factors relate to all stages of the process, together with the conditions for optimum working:

1. Finding the voluntary work experience that will meet your abilities and needs is important. People providing advice on voluntary work should be able to see your qualities. They should be able to guide you, put trust in you and find ways to support you. They should have connections with the neighbourhood, schools, municipality and other places.

2. The work should give positive experiences. You should be empowered to learn new, small things on an everyday basis, to be curious and to be challenged. The work should not be too fast or pressured.

3. The people involved are important. The peer group/ colleagues may be other people with mental health problems, which can be helpful as you 
are able to understand each other's problems and people show more respect and support each other. This makes a nice atmosphere to work and grow in. However, volunteering with other people, the broader community, also provides the opportunity to practice social relationships. The staff should be competent, understanding, supportive, cooperative, have bright ideas and give space to people.

4. The environment must provide a feeling of safety. This is very important as most of the time people with mental health problems have problems feeling safe in themselves, so it must come from the environment. It is also important to feel treated like a person instead of feeling like a number, as in many situations you meet. When you don't have a strong connection to family and friends and don't have a job, you can feel lost in society.

5. An ideal location is a place situated in society rather than in a clinical situation, working with or alongside people of all ages. It is also nice if it is close to nature and with plenty of light. These give more possibilities to be connected and involved with all kinds of people and situations and contribute to a good atmosphere. It is also good if it is close to your home; it helps your sense of connection with your local community, and reduces tiredness and so helps you save energy for other things.

6. The hours are important. It is good to have a structure, but it is also necessary sometimes to be flexible. Time is needed for rest, for reflection and for self-care and daily activities.

7. Financial support will be needed to buy materials, although for some activities you don't need so many. When you are able to sell things in a shop or a show-window in the building or outside you have a nice connection to those interested and the community. Financial support provided by disability funds/ social fund is also important, and acknowledges volunteer work as a relevant way for participation besides paid work.

\section{Conclusions}

Access to quality employment is seen to be a sustainable way out of social exclusion [13], and a key component of the European disability strategy 20102020 [11]. However, in the "doing" of social inclusion, the stories of the ELSiTO members show that paid em- ployment can be extremely difficult to find and maintain, in line with current figures on rates of unemployment amongst persons with mental illness [10].

The stories also demonstrate the ongoing attempts that people make to engage in purposeful, productive and satisfying occupations that will also enable them to be a useful part of society, confirming studies in this area [8]. For the members, engaging in meaningful and appreciated occupations, particularly work (of all kinds), enabled them to feel included, that they belonged, and supported their health.

While social inclusion is experienced at the individual, subjective level, it is evident that the ongoing commitment of members to achieve the best possible working arrangements for themselves is vitally influenced by objective factors, including structural barriers [22]. For many, voluntary work offered the most meaningful and health promoting opportunities, demonstrating the importance of its current promotion in national and European policies.

However, voluntary work, despite the current rhetoric, continues to be sharply divided from the "real" world of paid work, due to payment arrangements (from social security benefits rather than directly from the employing organisation), and societal attitudes (as something done by those who cannot work). It would seem necessary for society to recognise not only its prejudices against the mentally ill, but also against those who do not fit into contemporary understandings of (paid) workers, prejudices reinforced by the current neo-liberal policies [1]. Alongside this it would seem to be important to simplify the procedures around voluntary and paid work aiming for participation, benefits and salaries. This is a task that the Dutch government is currently undertaking in upcoming legislation for Working According to one's Abilities (Wet Werken naar Vermogen), with a focus on participation for all, focusing mainly on paid work, but including volunteer work [7].

Recognizing and utilizing the enormous potential of all workers is a challenge [15]. Understanding the complex interplay of subjective and objective factors in the process of social inclusion through work both paid and unpaid is an important element in the building of more inclusive communities and in promoting the health of the individual.

\section{Acknowledgements}

This article was prepared as part of the ongoing work of the ELSITO partnership and we would like to thank 
all members for their support and encouragement. Joint authors (members) contributed their stories under their own name, choosing full or first name. The complete stories of the members, from which excerpts are included in this article, together with more details of ELSiTO, are open to all at: www.elsito.net.

\section{References}

[1] Bourdieu, P. (1998). The essence of neoliberalism [Electronic Version]. Le Monde. Retrieved May 30, 2010 from http://www.analitica.com/bitblio/bourdieu/neoliberalism.asp.

[2] Burns, T., Catty, J., Becker, T., Drake, R., Fioritti, A., Knapp, M., et al. (2007). The effectiveness of supported employment for persons with severe mental illness: A randomised controlled trial. The Lancet, 370, 1146-1152.

[3] Busschbach , J. v. and Michon, H. (2011). Effectiviteit van individuele plaatsing en steun in Nederland. Verslag van een gerandomiseerde gecontroleerde effectstudie. (Effectiveness of IPS in the Netherlands. Report of a RCT.): Trimbos-instituut.

[4] Cook, S. and Chambers, E. (2009). What helps and hinders people with psychotic conditions doing what they want in their daily lives. British Journal of Occupational Therapy, 72(6), 238-248.

[5] COTEC. (2011). Position paper of the Council of occupational therapists for the European countries: European year of volunteering 2011. Retrieved August 12, 2011, from http://www.cotec-europe.org/userfiles/file/volontiranje.pdf.

[6] Davis, M. and Rinaldi, M. (2004). Using an evidence-based approach to enable people with mental health problems to gain and retain employment, education and voluntary work. British Journal of Occupational Therapy, 67(7), 319-322.

[7] Dutch Government. (2011). De Wet werken naar vermogen. Retrieved June 6, 2011, from http://www.rijksoverheid.nl/ onderwerpen/wet-werken-naar-vermogen-wwnv/de-wetwerken-naar-vermogen.

[8] Eklund, M. (2009). Work status, daily activities and quality of life among people with severe mental illness. Qual Life Res, 18, 163-170.

[9] Eklund, M., Leufstaduis, C. and Bejerholm, U. (2009). Time use among people with psychiatric disabilities: Implications for practice. Psychiatric Rehabilitation Journal, 32(3), 177191.

[10] European Commission. (2008). Mental Health in the EU Key Facts, Figures, and Activities. Retrieved November 12, 2010, from http://ec.europa.eu/health/archive/ph_determinants/life_ style/mental/docs/background_paper_en.pdf.
[11] European Commission. (2010). European Disability Strategy 2010-2020: A renewed commitment to a barrier-free Europe. Retrieved February 5, 2011, from http://eur-lex.europa.eu/ LexUriServ/LexUriServ.do?uri=COM:2010:0636:FIN:EN: PDF.

[12] European Commission. (2011). European year of volunteering 2011. Retrieved August 20, 2011, from http://ec.europa. eu/citizenship/focus/focus840_en.htm.

[13] European Council. (2009). Joint report on social protection and social inclusion. Retrieved September 10, 2010, from http://ec.europa.eu/social/main.jsp?catId=757\&langId=en.

[14] Eurostat. (2010). Combating poverty and social exclusion. A statistical portrait of the European Union 2010. Retrieved August 8, 2011, from http://epp.eurostat.ec.europa.eu/ cache/ITY_OFFPUB/KS-EP-09-001/EN/KS-EP-09-001-EN. PDF.

[15] Gabriel, P. and Liimatainen, M.-R. (2000). Mental health in the workplace. Geneva: International Labour Office.

[16] Gold, P. and Waghorn, G. (2007). Comment: Supported employment for people with severe mental illness. The Lancet, 370, 1108-1109.

[17] Koi.S.P.E. (2011). Odigos ton Koinonikon Synetairismon Periorismenis Euthinis (Koi.S.P.E.) (Guide to the Koi.S.P.E.). Athens: PEPSAEE.

[18] Mee, J., Sumsion, T. and Craik, C. (2004). Mental health clients confirm the value of occupation in building competence and self-identity. British Journal of Occupational Therapy, 67(5), 225-223.

[19] Paavola, S. and Hakkarainen, K. (2005). The knowledge creation metaphor - an emergent epistimological approach to learning. Science and Education, 14, 535-557.

[20] Royal College of Psychiatrists. (2009). Position Statement. Mental Health and Social Inclusion. Making Psychiatry and Mental Health Services Fit for the 21st Century. London: Royal College of Psychiatrists.

[21] Secker, J., Membrey, H., Grove, B. and Seebohm, P. (2002). Recovering from illness or recovering your life? Implications of clinical versus social models of recovery from mental health problems for employment support services. Disability and Society, 17(4), 403-418.

[22] Tregaskis, C. (2002). Social Model Theory: The story so far ... Disability and Society, 17(4), 457-470.

[23] UWV information on job coaching personal support. Retrieved October 3, 2011, from http://www.uwv.nl/zakelijk/reintegratiediensten/instrumenten-subsidies/jobcoach/index. aspx.

[24] Wilcock, A. (2006). An occupational perspective of health. Thorofare: Slack Incorporated.

[25] Wolfe, A. (1997). The moral meanings of work. The American Prospect, 34(14), 82-90. 